\title{
Short sleep duration as a risk factor for obesity in Kuwaiti children
}

\author{
Hend Alqaderi ${ }^{1}$, J. Max Goodson ${ }^{2}$, Mary Tavares ${ }^{2}$, Sabiha Al-Mutawa ${ }^{3}$, Jitendra Ariga ${ }^{4}$, Pramod Soparkar ${ }^{2}$, Jawad Behbehani ${ }^{5}$ and Kazem \\ Behbehani $^{6}$
}

${ }^{1}$ Department of Oral Health Policy and Epidemiology, Harvard School of Dental Medicine, 188 Longwood Ave, Boston, Massachusetts 02115, USA

${ }^{2}$ Department of Applied Oral Sciences, the Forsyth Research Institute, 245 First Street, Cambridge, Massachusetts 02142, USA

${ }^{3}$ Ministry of Health, Kuwait City, Behbehabi Building, Port Said Street, Bneid Alqar, Kuwait

${ }^{4}$ Kuwait School Oral Health Program, Salmia, Kuwait

${ }^{5}$ Faculty of Dentistry, Kuwait University, Health Science Centre, Jabria, Kuwait

${ }^{6}$ The Dasman Diabetes Institute, Alsoor Street, Kuwait City, Kuwait

Running Title: Short sleep duration as a risk factor for obesity

\begin{abstract}
The prevalence of obesity in Kuwaiti children is among the highest in the world. The aims of this study were to assess the role of short sleep duration as a risk factor in increasing abdominal obesity among Kuwaiti children, and to identify life style habits that contribute to sleep and obesity in this population. Waist circumference (WC) measurements, sleep evaluation interviews, and life style habits were collected from 8,371 children (10 y) from 185 schools representing all of the six governorates of Kuwait. Multivariate linear regression models were constructed to determine two different continuous outcomes; WC and daily sleep hours. Independent variables included TV and videogame use, difficulty breathing at night, participating in sports programs, and diabetic parents, adjusting for snacking, gender, and governorate. Short sleep duration was significantly associated with increased WC in Kuwaiti children (P<0.001). No significant association was detected between obesity and difficulty breathing at night $(\mathrm{P}=0.4)$. Watching TV or playing videogames before bedtime, as well as having TV in the bedroom were significant factors related to decreased sleep duration among Kuwaiti children $(\mathrm{P}<0.001)$. Short sleep duration is a significant risk factor that increased abdominal obesity among Kuwaiti children. Additionally, it was found that TV and videogame use were major risk factors contributing to decreased sleep duration and increased obesity among this population.
\end{abstract}

\section{Introduction}

Obesity in children is a growing global problem. No where is this felt to a greater extent than in Kuwait where, according to the International Diabetes Foundation every fourth adult has type 2 diabetes [1] and by our data every fourth 10 -year old child is obese. Given the high prevalence of obesity in Kuwaiti children, there are serious health implications for these children as they reach adulthood, given the fact that overweight in children is a predictor of obesity in adulthood [2]. Obesity is associated with an increased risk of costly chronic diseases, particularly cardiovascular disease and diabetes [3-6].

Studies report a remarkable decline in night sleep duration in several different populations, with a parallel substantial raise in the prevalence of obesity in these populations [7]. It has recently been suggested that inadequate sleep is a well-established risk factor associated with the development of obesity and metabolic syndrome [8-12].

One aim of this analysis was to determine the association between inadequate sleep as a risk factor for increased abdominal obesity. The majority of research related to sleep and obesity has been conducted in western countries, and shows that children who sleep less at night have significantly higher risk of becoming obese than children who sleep longer $[9,13]$. For these reasons, it seems logical to examine sleep duration as a risk factor for obesity in a population having the highest prevalence of adult obesity in the world; the Kuwaiti population [14]. There is a strong body of evidence showing that screen based activity has significantly contributed to decreased sleep time and increased obesity [15-17]. For this purpose we evaluated life style habits that might contribute to obesity in Kuwaiti children; such as TV and videogame factors (screen based activity).

\section{Materials and methods}

\section{Study approval}

This cross-sectional study was approved by the Forsyth Institutional Review Board in Cambridge MA, U.S.A. and the Dasman

Correspondence to: Hend Alqaderi, Department of Oral Health Policy and Epidemiology, Harvard School of Dental Medicine, 188 Longwood Ave, Boston, Massachusetts 02115, USA, Tel: 617-953-1384, Fax: 617-432-0047, E-mail: hend_alqaderi@hsdm.harvard.edu

Key words: obesity, children, sleep, television, life style.

Received: October 05, 2015; Accepted: November 10, 2015; Published: November 13, 2015 
Institute Human Ethical Review Committee in Kuwait (RA/065/2011 and RA/005/2011). Arabic language informed consent was provided to parents (or guardians) and assent provided to the children. Assent was obtained on the day of the study visit prior to participation in the study. Written consent forms were collected and securely stored at the School Oral Health Program of Kuwait.

\section{Study population}

Between October 2011 and May 2012, cross sectional data were collected from 8,317 children representing 185 public elementary schools in Kuwait. The Kuwaiti participants were in the $4^{\text {th }}$ or $5^{\text {th }}$ grades and their ages ranged between $8-11$ years old. There were approximately equal distributions of participants across the six governorates of Kuwait in the sample. Students enrolled in these schools represent all social levels and ethnic groups of Kuwaiti children but not expatriate children. All volunteers were accepted and selection into the cohort was not randomized across the population.

\section{Data collection}

Subject identification, body weight analysis, sleep evaluation interviews, nutrition analysis interviews, and life style habits information were collected by two calibrated teams. Information on these variables was recorded into a programmed iPad (Apple, Cupertino, CA) system for internet transfer.

\section{Outcome measures}

Two outcomes were assessed in this cross sectional study:

1) Waist circumference: WC was measured at the midpoint between the bottom of the rib cage and the top of the iliac crest at minimal respiration for each participant/subject. Each measurement was conducted using a paper anthropometry tape and the resulting circumference was rounded to the nearest centimeter.

2) Sleep duration: Each child was asked: 1) during the past week, at what time did you go to sleep? 2) During the past week, at what time did you wake up? On the weekend, what time do you normally go to sleep? 4) On the weekend, what time do you normally wake up? Based on the responses, the average number of sleep hours per day was calculated for each child.

\section{Explanatory covariates}

Predictors and potential confounding variables related to abdominal obesity and insufficient sleep tested in this study were: TV and videogame related factors, difficulties breathing at night, trouble falling to sleep, calorie intake, participating in sport programs, snacking, obesity, having diabetic mother or father, gender, and governorate of residence. These variables were obtained from one on one interview with each child by calibrated interviewers. An accounting of these covariates are summarized in the descriptive summary tables (Table $1 \mathrm{a}, 1 \mathrm{~b}, 2$, and 3).

Two separate multivariate linear regression analyses were conducted, one with WC, and another with sleep duration as continuous outcomes. Association parameters were estimated using the ordinary least squares method and subsequently assessed using Wald significance tests. The final models were determined using stepwise selection. All models were estimated in Stata 12 statistical software using the regress function. Two multivariate linear regression models were performed to identify the factors that contributed to abdominal obesity and short sleep duration.
Table 1a. Population descriptive statistics (mean \pm s.d.). P values computed by two-sample t-test with sex as the grouping variable.

\begin{tabular}{|c|c|c|c|}
\hline Variable & Boys (n=3,219) & Girls (n=5,098) & P value \\
\hline Age (y) & $9.9 \pm 0.67$ & $9.9 \pm 0.67$ & 0.5 \\
\hline Waist circumference (cm) & $68.9 \pm 23.5111116 .3$ & $68.6 \pm 16.3$ & 0.6 \\
\hline Daily sleep (h) & $8.8 \pm 1.65$ & $8.8 \pm 1.61$ & 0.7 \\
\hline Weight (kg) & $40.3 \pm 13.8$ & $40.8 \pm 32.5$ & 0.4 \\
\hline Height (cm) & $137.1 \pm 9.4$ & $137.6 \pm 9.4$ & 0.03 \\
\hline Body Mass Index (kg/m²) & $21.0 \pm 5.4$ & $20.8 \pm 5.2$ & 0.3 \\
\hline Systolic blood pressure (mmHg) & $110.3 \pm 17.5$ & $108.9 \pm 15.4$ & $<0.001$ \\
\hline Diastolic blood pressure (mmHg) & $74.6 \pm 13.9$ & $74.1 \pm 24.1$ & 0.2 \\
\hline
\end{tabular}

Table 1b. Summary of body weight distribution by BMI percentile and waist circumference. Percent differences between sexes were all highly significant by Pearson chi-square analysis $(\mathrm{p}<0.001)$.

\begin{tabular}{|c|c|c|c|}
\hline $\begin{array}{c}\text { Overweight and obesity by } \\
\text { BMI percentile }\end{array}$ & $\begin{array}{c}\text { Total Number } \\
\text { (Proportion) }\end{array}$ & Boys & Girls \\
\hline Underweight $\left(<5^{\text {th }}\right)$ & $193(2.3 \%)$ & $63(2.0 \%)$ & $130(2.6 \%)$ \\
\hline $\begin{array}{c}\text { Normal Healthy weight } \\
\left(\geq 5^{\text {th }}<85^{\text {th }}\right)\end{array}$ & $4,129(49.6 \%)$ & $1,528(47.5 \%)$ & $2,601(51.0 \%)$ \\
\hline Overweight $\left(\geq 85^{\text {th }}\right.$ to $\left.<95^{\text {th }}\right)$ & $1,791(21.5 \%)$ & $621(19.3 \%)$ & $1,170(23.0 \%)$ \\
\hline Obese $\left(\geq 95^{\text {th }}\right)$ & $2,204(26.5 \%)$ & $1,007(31.3 \%)$ & $1,197(23.5 \%)$ \\
\hline Obese by waist circumference & $1,914(23.1 \%)$ & $688(21.4 \%)$ & $1,226(24.1 \%)$ \\
\hline
\end{tabular}

Table 2. Obesity proportion based on governorates and family origin.

\begin{tabular}{|c|c|c|}
\hline Governorate & $\begin{array}{c}\text { Obesity by BMI } \\
\text { percentile (WHO) }\end{array}$ & $\begin{array}{c}\text { Obesity by waist } \\
\text { circumference }\end{array}$ \\
\hline Ahmadi (Bedouin) & $20.8 \%$ & $17.5 \%$ \\
\hline Jahra (Bedouin) & $23.6 \%$ & $21.2 \%$ \\
\hline $\begin{array}{c}\text { Mubarak Alkabeer } \\
\text { (Mostly Bedouin) }\end{array}$ & $24.8 \%$ & $28.4 \%$ \\
\hline $\begin{array}{c}\text { Farwania } \\
\text { (Mostly Bedouin) }\end{array}$ & $26.2 \%$ & $27.2 \%$ \\
\hline $\begin{array}{c}\text { Hawali } \\
\text { (Mix Saudi and Persian) }\end{array}$ & $30.0 \%$ & $24.0 \%$ \\
\hline $\begin{array}{c}\text { Capital } \\
\text { (Mix Saudi and Persian) }\end{array}$ & $33.4 \%$ & $24.6 \%$ \\
\hline
\end{tabular}

The first model was conducted using WC as the outcome to represent abdominal obesity. Recent evidence shows that increased WC compared with Body Mass Index (BMI) measurements has a stronger correlation with diabetes, cardiovascular diseases, and some cancers [18]. We first examined the univariate relationship between WC and daily sleep hours, and then we included other obesityrelated independent variables such as TV and videogame variables simultaneously using stepwise selection. Model selection was based on clinical relevance and a predetermined significance level of $\alpha=0.05$.We kept all significant variables in the final model as well as the potential confounders (Table 4).

The second model evaluated the relationship between daily sleep hours as the outcome with life-style risk factor variables related to sleep curtailment as the explanatory variables. The stepwise selection method was used to determine a parsimonious model. The explanatory variables considered for selection were TV and videogame factors, having diabetic parents, and adjusting for obesity, snacking, gender and governorate (Table 5). 
Table 3. Summary descriptions of life style habits. P values apply to differences between boys and girls by chi square analysis. (VG=video games).

\begin{tabular}{|c|c|c|c|c|}
\hline \multirow[t]{2}{*}{ Life style habit variables } & \multirow{2}{*}{ Total percentage } & Boys & Girls & \multirow[t]{2}{*}{ P value } \\
\hline & & \multicolumn{2}{|c|}{ Number (percentage) } & \\
\hline Have TV in bedroom & $40.3 \%$ & $1.634(51.2 \%)$ & $1.721(33.6 \%)$ & $<0.001$ \\
\hline Watch TV and play VG before bedtime** & $86 \%$ & $2.841(89 \%)$ & $4.326(84 \%)$ & $<0.001$ \\
\hline $\begin{array}{l}\text { Watch TV or play VG more than two hours } 4 \text { days a week } \\
\text { or more* }\end{array}$ & $82 \%$ & $2.580(80.8 \%)$ & $4.238(82.5 \%)$ & 0.07 \\
\hline Eat in front of TV 4 days a week or more* & $65.6 \%$ & $2.092(65.6 \%)$ & $3.370(65.7 \%)$ & 0.09 \\
\hline Use bed for watch TV and play VG ** & $37 \%$ & $1.052(33 \%)$ & $2.132(39.5)$ & $<0.001$ \\
\hline Participate in sport program outside school & $21.8 \%$ & $1.071(33.9 \%)$ & $730(14.4 \%)$ & $<0.001$ \\
\hline Trouble breathing at night** & $11 \%$ & $350(10 \%)$ & $567(11 \%)$ & 0.9 \\
\hline Trouble falling to sleep** & $19.8 \%$ & $647(20 \%)$ & $1.001(19.5 \%)$ & 0.3 \\
\hline Have diabetic mother & $8 \%$ & $257(8 \%)$ & $404(7.8 \%)$ & 0.3 \\
\hline Have diabetic father & $14 \%$ & $451(14.3 \%)$ & $714(13.8 \%)$ & 0.01 \\
\hline Snacking & $98.3 \%$ & $3.110(98 \%)$ & $5.029(98.5 \%)$ & 0.2 \\
\hline
\end{tabular}

*Ordinal variable for use during weekdays.

**Ordinal variable (never, rarely, sometimes, often).

The result presented for the sometimes and often $v s$. never and rarely

Table 4. First multivariate linear regression model with waist circumference as the outcome.

\begin{tabular}{|c|c|c|c|}
\hline Covariate & Estimate (se) & P value & Confidence Interval \\
\hline Daily sleep hours (continuous) & $-0.4(0.13)$ & 0.002 & $-0.66,-0.14$ \\
\hline Having TV in bedroom* & $1.3(0.44)$ & 0.003 & $-2.16,-0.42$ \\
\hline Trouble breathing at night $* *$ & $0.54(0.71)$ & 0.4 & $-0.86,1.95$ \\
\hline Trouble falling to sleep $* *$ & $1.8(0.56)$ & 0.001 & $0.7,2.93$ \\
\hline Frequency of snacking* & $0.6(1.7)$ & 0.7 & $-3.95,2.71$ \\
\hline Gender * & $0.7(0.46)$ & 0.1 & $-0.14,1.63$ \\
\hline \multicolumn{4}{|l|}{ Governorate (Reference: Capital) } \\
\hline Ahmadi & $-2.3(0.6)$ & 0.001 & $-3.6,-1.005$ \\
\hline Jahra & $-0.9(0.6)$ & 0.1 & $1.0,3.6$ \\
\hline Hawalli & $0.4(0.7)$ & 0.5 & $-0.06,1.9$ \\
\hline Farwania & $1.4(0.7)$ & 0.03 & $0.07,2.8$ \\
\hline Mubarak Alkabeer & $3.7(0.87)$ & $<0.0001$ & $2.0,5.4$ \\
\hline
\end{tabular}

*Binary variables

** Ordinal variable of 4 categories (no, rarely, sometimes, often) was used as a continuous variable.

\section{Results}

The population descriptive statistics for the analysis are summarized in table 1a. There were more girls in the study than boys. The age of children was tightly clustered around 10 years old. The mean WC for boys was $68.9 \mathrm{~cm}$ and $68.6 \mathrm{~cm}$ for girls. On average, both boys and girls slept 8.8 hours/day.

BMI was slightly higher in boys $(\mathrm{p}=0.03)$ and the mean systolic blood pressure was significantly higher in boys $(\mathrm{p}<0.001)$.

Table $1 \mathrm{~b}$ summarizes the distribution of body weight categories by BMI percentile and by WC according WHO guidelines [19]. BMI percentile identified $3.4 \%$ more obese children than WC. By BMI percentile there was a significantly higher percentage of obese boys $(\mathrm{p}<0.001)$. By WC, there was a significantly higher percentage of obese girls $(p=0.004)$. The Pearson correlation between categorization of obesity by the two methods was $0.7(\mathrm{p}<0.001)$.

Kuwait is divided into six governorates. As indicated in Table 2, the percentage of children classified as obese by BMI percentile and by WC are compared for each governorate. By both methods, the lowest percentage obese children were in the Bedouin communities of Ahmadi and Jahra. The largest percentage obese by BMI percentile was Capital whereas by WC it was Mubarak Alkabeer. These communities are populated by mixtures of Saudi and Persian descent as are the governorates of Hawali and FARWANIA. It is likely that the significance of governorates in regression models is related to this genetic segregation.

The results from the first multivariate linear regression model with WC as the outcome are shown in Table 4. The model shows that short sleep duration significantly predicts increased abdominal obesity among the Kuwaiti children $(\mathrm{P}<0.002)$, with significant variation between governorates. After adjusting for gender and snacking, children residing in Jahra and Ahmadi governorates had a lower estimate of abdominal obesity than other governorates whereas children living in Hawalli, Farwania and Mubarak Alkabeer had a higher estimate of obesity. These observations are consistent with those of Table 2.

Children who had TV in their bedrooms tended to have a larger 
Table 5. Second multivariate linear regression model with daily sleep hours as the outcome variable.

\begin{tabular}{|c|c|c|c|}
\hline Factor & Estimate (se) & P value & Confidence interval \\
\hline Watching TV or play videogames before bedtime* & $-0.26(0.05)$ & $<0.001$ & $-0.36,-0.16$ \\
\hline Using bed for watching TV or playing videogames* & $-0.13(0.03)$ & $<0.001$ & $-0.2,-0.06$ \\
\hline $\begin{array}{c}\text { Watching TV and playing videogames more than } 2 \text { hours } 4 \text { days a week or } \\
\text { more** }\end{array}$ & $-0.15(0.002)$ & 0.001 & $-0.24,-0.05$ \\
\hline Eating in front of the TV every day more than 2 hours 4 days a week or more** & $-0.22(0.03)$ & $<0.001$ & $-0.3,-0.15$ \\
\hline Participating in a sport program outside the school (yes vs. no) & $0.08(0.04)$ & 0.06 & $-0.17,-0.005$ \\
\hline Have diabetic father & $-0.16(0.05)$ & 0.001 & $-0.06,-0.26$ \\
\hline Have diabetic mother (yes vs. no) & $-0.28(0.06)$ & $<0.001$ & $-0.14,-0.4$ \\
\hline Obese (binary variable by WHO percentile) & $0.14(0.04)$ & $<0.001$ & $-0.22,-0.06$ \\
\hline Snacking (yes $v s$. no) & $0.02(0.1)$ & 0.8 & $-0.25,0.3$ \\
\hline Sex (boys vs. girls) & $0.0003(0.03)$ & 0.9 & $-0.074,-0.075$ \\
\hline \multicolumn{4}{|l|}{ Governorate (Reference: Capital) } \\
\hline Ahmadi & $-0.04(0.05)$ & 0.4 & $-0.15,0.06$ \\
\hline Jahra & $-0.26(0.05)$ & $<0.001$ & $-0.37,-0.1$ \\
\hline Hawalli & $0.02(0.06)$ & 0.6 & $-0.09,0.15$ \\
\hline Farwania & $-0.1(0.06)$ & 0.06 & $-0.2,0.007$ \\
\hline Mubarak Alkabeer & $0.18(0.07)$ & 0.01 & $0.03,0.32$ \\
\hline
\end{tabular}

* Ordinal variable for use during weekdays.

** Ordinal variable (never, rarely, sometimes, often). The result presented for the sometimes and often vs. never and rarely

WC than children who did not $(\mathrm{P}<0.003)$. There was no significant association between obesity and trouble breathing during sleep that could be a proxy for obstructive sleep apnea $(\mathrm{P}=0.4)$. Frequency of snacking (binary yes or no) had no significant effect on the model which is not surprising since $98.3 \%$ of the children reported "yes" (Table 3 ).

Results from the second multivariate regression model with daily sleep hours as the outcome variable (Table 5), revealed that the main factors that predict short sleep duration in children were screen based activity factors; we found that watching TV or playing videogames before bedtime significantly reduced daily sleep hours $(\mathrm{p}<0.001)$. Moreover, using the bedroom for watching TV and playing videogames significantly predicted shorter sleep duration $(\mathrm{p}<0.001)$. Playing videogames or watching TV more than 2 hours a day also significantly reduced daily sleep hours $(\mathrm{p}<0.01)$, as well as eating in front of the TV $(\mathrm{p}<0.001)$. Additionally, we found that that children with a diabetic parent slept significantly less than children of non-diabetic parents $(\mathrm{p}<0.001)$. This model was adjusted for obesity, snacking, gender, and governorate.

\section{Discussion}

In the present study, the mean WC for Kuwaiti children ages 8-11 years old was $68.6 \pm 0.2 \mathrm{~cm}$ with no significant difference between boys and girls. Comparing this with WC in other countries such as USA, Australia, UK, Turkey, Japan, Spain, and UK; Kuwait has the highest mean WC worldwide $[18,20]$. We used WC as the main outcome to represent abdominal obesity because WC has been strongly correlated with cardiovascular diseases, diabetes, and some cancers. The correlation between WC and these diseases is stronger withWC than with BMI percentile [18]. In this study, short sleep duration was significantly associated with increased WC $(\mathrm{P}<0.002)$. The magnitude and the direction of the relationship between obesity and sleep duration is consistent with other studies of children in different populations [7].

\section{Relation between short sleep duration and obesity}

It has been observed that inadequate sleep in healthy subjects is associated with significant hormonal imbalance resulting in increased food intake and snacking [21]; this may affect appetite regulation and glucose metabolism and eventually leads to the development of diabetes and cardiovascular disease [11,21]. According to the Centers of Disease Control and Prevention (CDC) and the pediatric clinical guide for sleep [22], 10-11 hours of sleep are considered a healthy average sleep duration for 8-11 year-old children. Our data showed that the mean sleep duration was $8.8 \pm 1.6$ hours, which is less than the healthy average recommended hours. These results suggest that inadequate sleep may be an obesity risk factor that is prevalent in this population. It has been suggested that children and adolescents may be more vulnerable to the effects of inadequate sleep duration than adults $[7,10]$. The association between obesity and short sleep may be a bidirectional due to the possibility of preexisting Obstructive Sleep Apnea (OSA) [23]. It has been suggested that obese individuals are more likely to have inadequate sleep because of the OSA. However, the relation between OSA and obesity in adolescent might be negative in some populations [24]. In this study, we asked the children if they have trouble breathing at night as an indicator for OSA and to examine its relation with abdominal obesity. There was no significant association between having trouble breathing during sleep, suggesting that OSA indicator was not a significant factor related to obesity among Kuwaiti children. 
There is evidence that sleep deprivation and disrupted circadian rhythm in shift workers are associated with obesity and type2 diabetes [25]. Moreover, individuals who have sufficient high-quality sleep have higher levels of melatonin; a hormone secreted by the pineal gland during sleep at nighttime [12]. Melatonin plays a crucial role in the maintenance of circadian rhythm and regulates nighttime sleep [26]. In addition, melatonin has been reported to play an important role in carbohydrate metabolism and insulin regulation [11]. It has been shown that light-at-night-induced suppression of melatonin secretion resulting in reductions in sleep duration $[12,26]$. Consequently, persons who have insufficient sleep are at risk of cardio-metabolic impairments caused by melatonin disruption that include obesity and other associated metabolic syndromes [27]. Thus, if life-style changes were implemented by improving sleep quality, metabolic hormonal balance could improve and susceptibility for obesity would decrease.

\section{Short sleep duration and the frequency of use TV and videogames}

In this study, we found that children who frequently watch TV or play videogames just before bedtime sleep significantly less than children who rarely or never watch TV or play videogames before bedtime $(\mathrm{P}<0.001)$. Similarly, children who mostly use their beds for watching TV and playing videogames significantly slept less than children who rarely or never used their beds for the screen-based activity $(\mathrm{P}<0.001)$. In the present analysis, screen based activities factors were the most significant factors that contributed to reduce night sleep duration among Kuwaiti children. We found that children who watch TV or play videogames more than two hours most weekdays and those who eat in front of the TV most weekdays sleep significantly less than other children $(\mathrm{P}<0.001)$. In contrast, children who participated in sport programs outside of school tend to sleep more hours $(\mathrm{P}=0.06)$, suggesting that being physically active and minimizing screen based activity might contribute to improve sleep duration.

In this study, $40.3 \%$ of the Kuwaiti children have TVs in their bedrooms (Table 3 ), and $86 \%$ of the children watch TV or play videogames just before going to bed. Additionally, $82 \%$ of the children are watching TV and playing videogames for more than two hours on most weekdays, while only $21.8 \%$ participate in sports programs. These are alarming findings that may explain the general reduction in the sleep duration among these children.

It has been shown that short sleep duration and use of electronic devices are associated with excess body weight [28]. Using technology for long periods can suppress melatonin secretion [29]. Moreover, it has been suggested that short wavelength light from electronic devices significantly inhibits melatonin secretion resulting in delayed sleep and diminished quality of sleep [28]. A randomized study found that individuals who used electronic books before bed time have decreased evening sleep and have lower level of melatonin secretion than individuals used printed books [30]. As mentioned earlier, melatonin has an important role in carbohydrate metabolism and insulin regulation [26].

In the present study there was a positive significant association between screen based activity factors, insufficient sleep, and obesity. This supports the hypothesis that disturbance of melatonin secretions by long exposure to electronics devices and inadequate sleep can promote the inflammation in the body through hormonal disruption and potentially can lead to abnormal weight gain, independent of the amount of caloric intake. Additionally, we found that children of diabetic parents significantly sleep less (Table 5) than children who have non-diabetic children $(\mathrm{P}<0.001)$. Giving the fact that short sleep duration is related to diabetes and metabolic diseases, this might be attributed to the family life style factor; potentially, parents who don't value sufficient night sleep may let their children stay up late and these parents are more susceptible to be diabetic.

\section{Obesity and the frequency of TV and videogames use}

In the present study, we found that $65.6 \%$ of the children reported eating in front of the TV on most weekdays (Table 3). Children who have TV in their bedrooms (Table 4) significantly have more abdominal obesity than children who don't have TVs in their bedroom $(\mathrm{P}<0.01)$. Screen based activity has been considered a major public health issue that is associated with unexpected health conditions [16] Independent of physical activity, adolescents who spend excessive time in screen-based activities are more prone to obesity [29,31]. Strong association has been consistently observed between the presence of the TV in the bedroom and weight gain, mediated by TV viewing time [29,32]. Moreover, screen-based activities have been shown to divert children's attention away from the control of food intake, and eventually distracting them from signals of satiety [33-35]. It has been found that the desire to eat fast foods may be increased by TV viewing due to the pairing mechanism between eating fast food and TV viewing overtime $[35,36]$. This conditioning may also be related to the child's exposure to the unhealthy TV food advertisements [35]. Other studies that explain the relation between TV and overeating found that TV has a negative effect on memory; participants were less able to accurately estimate their food intake while watching TV [35-37].

\section{Environmental factors}

Within Kuwait there are clusters of inhabitants with differing social class, ethnicity, and family origin. There are three identified ethnic groups in Kuwait based on the family origin and tribal background; Bedouin, Saudi, and Persian [38]. Each ethnic group is known by certain characteristics and specific life habits that eventually could shape health behaviors and outcomes in this population. A recent genetic study in Kuwait has shown that there is distinct genetic difference among the three ethnic groups and they recommended considering ethnic assessment in public health practice to target risk groups for health intervention programs [38]. In this study we found differences in the proportion and magnitude of obesity between the six governorates of Kuwait (Table 2 and 4). Ahmadi and Jahra governorates are considered Bedouin governorates. These two Bedouin governorates have lower obesity percentage compared to other governorates who have mixed of Saudi and Persian community (Table 2 and Table 4). From our knowledge about Kuwaiti population, Bedouins communities likely have a lower socioeconomic status with less accessibility to restaurants and technology and appear to have become less obese than Saudi and Persian populations within Kuwait.

The hot climate in Kuwait clearly contributes to promotion of a sedentary life style among the Kuwaiti population. The weather is extremely hot during most of the year days with a temperature exceeding $50^{\circ} \mathrm{C}$. The lack of awareness of the negative effect of the electronic devises with the scarcity of the indoor sport programs can also substantially contribute to the extreme use of screen base activity as an available alternative to indoor entertainment in this hot environment.

\section{Conclusion}

Short sleep duration is a significant risk factor associated with 
increased abdominal obesity among Kuwaiti children. Screen based activities is a major issue contributing to reduced sleep time and increased obesity. Public health interventions should target children and their families to improve their life style habits by having sufficient night sleep as well as limit screen time in addition to maintaining healthy eating and being physically active.

\section{Acknowledgment}

The present study was funded by Dasman Diabetes Institute in Kuwait (RA/065/2011 and RA/005/2011).The authors of this review received no financial support and declare no potential conflicts of interest with respect to the authorship and/or publication of this article.

\section{References}

1. Belgium B (2011) International Diabetes Federation.

2. Field AE, Cook NR, Gillman MW (2005) Weight status in childhood as a predictor of becoming overweight or hypertensive in early adulthood. Obes Res 13: 163-169. [Crossref]

3. Freedman DS, Dietz WH, Srinivasan SR, Berenson GS (1999) The relation of overweight to cardiovascular risk factors among children and adolescents: the Bogalusa Heart Study. Pediatrics 103: 1175-1182. [Crosssref]

4. Ford ES, Galuska DA, Gillespie C, Will JC, Giles WH, et al. (2001) C-reactive protein and body mass index in children: findings from the Third National Health and Nutrition Examination Survey, 1988-1994. J Pediatr 138: 486-492. [Crossref]

5. Ferguson MA, Gutin B, Owens S, Litaker M, Tracy RP, et al. (1998) Fat distribution and hemostatic measures in obese children. Am J Clin Nutr 67: 1136-1140. [Crossref]

6. Tounian P, Aggoun Y, Dubern B, Varille V, Guy-Grand B, et al. (2001) Presence of increased stiffness of the common carotid artery and endothelial dysfunction in severely obese children: a prospective study. Lancet 358: 1400-1404. [Crossref]

7. Cappuccio FP, D'Elia L, Strazzullo P, Miller MA (2010) Sleep duration and all-cause mortality: a systematic review and meta-analysis of prospective studies. Sleep 33: 585592. [Crossref]

8. Narang I, Manlhiot C, Davies-Shaw J, Gibson D, Chahal N, et al. (2012) Sleep disturbance and cardiovascular risk in adolescents. CMAJ 184: E913-E920. [Crossref]

9. Knutson KL (2012). Does inadequate sleep play a role in vulnerability to obesity? Am J Hum Biol 24: 361-371. [Crossref]

10. Danielsen YS, Pallesen S, Stormark KM, Nordhus IH, Bjorvatn B (2010) The relationship between school day sleep duration and body mass index in Norwegian children (aged 10-12). Int J Pediatr Obes 5: 214-220. [Crossref]

11. Srinivasan V, Ohta Y, Espino J, Pariente JA, Rodriguez AB, et al. (2013) Metabolic syndrome, its pathophysiology and the role of melatonin. Recent Pat Endocr Metab Immune Drug Discov 7: 11-25. [Crossref]

12. McMullan CJ, Schernhammer ES, Rimm EB, Hu FB, Forman JP (2013) Melatonin secretion and the incidence of type 2 diabetes. JAMA 309: 1388-1396. [Crossref]

13. Cappuccio FP, Taggart FM, Kandala NB, Currie A, Peile E, et al. (2008) Meta-analysis of short sleep duration and obesity in children and adults. Sleep 31: 619-626. [Crossref]

14. Al Rashdan I, Al Nesef Y (2010) Prevalence of overweight, obesity, and metabolic syndrome among adult Kuwaitis: results from community-based national survey. Angiology 61: 42-48. [Crossref]

15. Thorp AA, Healy GN, Owen N, Salmon J, Ball K, et al. (2010) Deleterious associations of sitting time and television viewing time with cardiometabolic risk biomarkers: Australian Diabetes, Obesity and Lifestyle (AusDiab) study 2004-2005. Diabetes Care 33: 327-34. [Crossref]

16. Li C, Beech B, Crume T, D'Agostino RB Jr, Dabelea D, et al. (2015) Longitudinal association between television watching and computer use and risk markers in diabetes in the SEARCH for Diabetes in Youth Study. Pediatr Diabetes 16: 382-391. [Crossref]

17. Katzmarzyk PT, Barreira TV, Broyles ST, Champagne CM, Chaput JP, et al. (2015) Relationship between lifestyle behaviors and obesity in children ages 9-11: Results from a 12-country study. Obesity (Silver Spring)23: 1696-16702. [Crossref]

18. Hatipoglu N, Ozturk A, Mazicioglu MM, Kurtoglu S, Seyhan S, et al. (2008) Waist circumference percentiles for 7- to 17-year-old Turkish children and adolescents. Eur J Pediatr 167: 383-9. [Crossref]
19. de Onis M, Onyango AW, Borghi E, Siyam A, Nishida C, et al. (2007) Development of a WHO growth reference for school-aged children and adolescents. Bull World Health Organ 85: 660-667. [Crossref]

20. McCarthy HD, Jarrett KV, Crawley HF (2001) The development of waist circumference percentiles in British children aged 5.0-16.9 y. Eur J Clin Nutr 55: 902-907. [Crossref]

21. Hanlon EC, Van Cauter E (2011) Quantification of sleep behavior and of its impact on the cross-talk between the brain and peripheral metabolism. Proc Natl Acad Sci U S A 108 Suppl 3: 15609-15616. [Crossref]

22. 22. Mindell JOJ (2003) A clinical guide to pediatric sleep. Diagnosis and Management of Sleep Disorder. Philadelphia, PA: Lippincott Williams \& Wilkins.

23. Gileles-Hillel A, Alonso-Alvarez ML, Kheirandish-Gozal L, Peris E, Cordero-Guevara JA, et al. (2014) Inflammatory markers and obstructive sleep apnea in obese children: the NANOS study. Mediators Inflamm.

24. Erdim I, Akcay T, Yilmazer R, Erdur O, Kayhan FT (2015) Is Metabolic Syndrome Associated With Obstructive Sleep Apnea in Obese Adolescents? J Clin Sleep Med. [Crossref]

25. Haus EL, Smolensky MH (2013) Shift work and cancer risk: potential mechanistic roles of circadian disruption, light at night, and sleep deprivation. Sleep Med Rev 17: 273-284. [Crossref]

26. Hardeland R, Cardinali DP, Srinivasan V, Spence DW, Brown GM, et al. (2011) Melatonin--a pleiotropic, orchestrating regulator molecule. Prog Neurobiol 93: 350384. [Crossref]

27. Schwimmer JB, Burwinkle TM, Varni JW (2003) Health-related quality of life of Severely Obese Children And Adolescents. JAMA 289: 1813-1819. [Crossref]

28. Wood B, Rea MS, Plitnick B, Figueiro MG (2013) Light level and duration of exposure determine the impact of self-luminous tablets on melatonin suppression. Appl Ergon 44: 237-240. [Crossref]

29. Arora T, Hosseini-Araghi M, Bishop J, Yao GL, Thomas GN, et al. (2013) The complexity of obesity in U.K. adolescents: relationships with quantity and type of technology, sleep duration and quality, academic performance and aspiration. Pediatr Obes 8: 358-366. [Crossref]

30. Chang AM, Aeschbach D, Duffy JF, Czeisler CA (2015) Evening use of light-emitting eReaders negatively affects sleep, circadian timing, and next-morning alertness. Proc Natl Acad Sci U S A 112: 1232-1237.

31. Rey-López JP, Ruiz JR, Vicente-Rodríguez G, Gracia-Marco L, Manios Y, et al. (2012) Physical activity does not attenuate the obesity risk of TV viewing in youth. Pediatr Obes 7: 240-50. [Crossref]

32. Borghese MM, Tremblay MS, Katzmarzyk PT, Tudor-Locke C, Schuna JM, et al (2015) Mediating role of television time, diet patterns, physical activity and sleep duration in the association between television in the bedroom and adiposity in 10 yearold children. Int J Behav Nutr Phys Act 12: 60. [Crossref]

33. Hetherington MM, Anderson AS, Norton GN, Newson L (2006) Situational effects on meal intake: A comparison of eating alone and eating with others. Physiol Behav 88: 498-505. [Crossref]

34. Temple JL, Giacomelli AM, Kent KM, Roemmich JN, Epstein LH (2007) Television watching increases motivated responding for food and energy intake in children. $\mathrm{Am} J$ Clin Nutr 85: 355-61. [Crossref]

35. Marsh S, Ni Mhurchu C, Maddison R (2013) The non-advertising effects of screenbased sedentary activities on acute eating behaviours in children, adolescents, and young adults. A systematic review. Appetite 71: 259-273. [Crossref]

36. Higgs S, Woodward M (2009) Television watching during lunch increases afternoon snack intake of young women. Appetite, 52, 39-43. [Crossref]

37. Moray J, Fu A, Brill K, Mayoral MS (2007) Viewing Television While Eating Impairs the Ability to Accurately Estimate Total Amount of Food Consumed. Bariatric Nursing and Surgical Patient Care 2: 71-76.

38. Alsmadi O, Thareja G, Alkayal F, Rajagopalan R, John SE, et al. (2013) Genetic substructure of Kuwaiti population reveals migration history. PLoS One 8: e74913. [Crossref]

Copyright: (C2015 Alqaderi H. This is an open-access article distributed under the terms of the Creative Commons Attribution License, which permits unrestricted use, distribution, and reproduction in any medium, provided the original author and source are credited. 